\title{
SAR COHERENCE CHANGE DETECTION OF URBAN AREAS AFFECTED BY DISASTERS USING SENTINEL-1 IMAGERY.
}

\author{
Prosper Washaya ${ }^{1}$, Timo Balz ${ }^{1,2 *}$ \\ ${ }^{1}$ State Key Laboratory of Information Engineering in Surveying, Mapping and Remote Sensing, Wuhan University, Wuhan \\ 430072, China; \\ ${ }^{2}$ Collaborative Innovation Center for Geospatial Technology, Wuhan 430072, China
}

KEY WORDS: SAR, Coherence Change Detection, Coherence maps, Hurricane, earthquake

\begin{abstract}
:
The study focuses on two study areas: San Juan in Puerto Rico, which was affected by Hurricane Maria in September 2017, and Sarpol Zahab in Iran, which was one of the towns affected by an earthquake in November 2017. In our study, we generate coherence images, and classify them into areas of 'change' and 'no-change'. A statistical analysis is made by converting the coherence results into point data, creating street blocks for the study areas and integrating the point data into the street blocks to calculate the standard deviation over the whole stack of images. Additionally, Landsat imagery is used to create land-use classes, convert them to polygons and integrate the polygon classes to the coherence maps to determine the average coherence loss per class for each disaster. Results show $65 \%$ loss in coherence after the earthquake in Sarpol-e-Zahab and 75\% loss in Puerto Rico after the Hurricane. Land-use classes show coherence losses to below 0.5 for each disaster.
\end{abstract}

\section{INTRODUCTION}

Natural disasters are devastating and result in serious damages on various facets of development especially in urban areas where population has become increasingly concentrated. Natural disasters refer to the natural processes that occur in the ecosystem, which can lead to the loss of stability of the social-economic system, and serious imbalance between supply and demand of social resources (Zhou et al., 2017). These are generally separated into six broad categories; marine disasters, meteorological disasters, geological disasters, environmental pollution disasters, fire, and biological disasters (Yi et al., 2011).

For disaster monitoring and management, rapid, reliable and continuous information is an essential requirement. Remote sensing data provides a solution for rapid data acquisition and post disaster information to assist in disaster monitoring (Rana et al., 2010; Wang \& Xu, 2010). In earthquake disasters, it essential to obtain information about damages resulting from these disasters using remote sensing. Previous studies have adopted high resolution satellite imagery (Li et al., 2011), SAR imagery (Matsuoka and Yamazaki, 2006) for disaster monitoring.

Landsat 8 imagery has been used to monitor the recovery process in New Orleans and the surrounding area based on remote sensing ten years after Hurricane Katrina (Li et al., 2016). In this study, results indicated that on average conditions for vegetation in the areas that were affected have not recovered fully as compared to the conditions before the disaster. Additionally, remote sensing can be used to monitor building destruction in post-disaster scenarios. (Marx, 2016) capitalizes on the advantage of Landsat imagery's ability to provide archive data to identify when urban buildings are destroyed during the Syrian civil conflict. However, optical imagery is reliant on passive sensors, therefore it is affected by extreme and unfavorable weather conditions making it unsuitable in monitoring areas affected by hurricanes, which may have prolonged cloud cover. Synthetic Aperture Radar (SAR), on the other hand, operates on an active sensor, and has the ability to obtain data anytime of the day and in almost any weather (Dong et al., 2011).

Using the coherence characteristics of SAR images, the study applied the Coherence Change Detection Technique using Sentinel-1 imagery, which has a large-scale global mapping capability and operates independent of weather and light (Potin et al., 2016) to monitor disaster induced urban changes. The CCD technique is not a new remote sensing technique and has been applied in various studies to monitor urban changes ( $\mathrm{He}$ and $\mathrm{He}$, 2009; Jendryke et al., 2016; Jendryke et al., 2017; Liao et al., 2006). However, despite efforts made by the above studies, availability of large-scale global data- with an all-day and allweather convenience- is not taken into account. This study, therefore, utilizes SAR images using the CCD technique by exploiting the above advantages with an understanding that such reliable data is crucial in disaster areas where timely availability of data is a requirement.

\section{STUDY AREAS}

The study focuses on Sarpol-e-Zahab, Iran and San Juan, Puerto Rico, which were affected by an earthquake disaster and a hurricane, respectively. Sarpol-e-Zahab was devastated by a magnitude 7.3 earthquake that was the strongest recorded earthquake since 1967 and devastated the border between IranIraq, it was the strongest on record in the region since 1967. In

\footnotetext{
* Corresponding author - balz@whu.edu.cn
} 
Puerto Rico, Hurricane Maria caused catastrophic damage on the $20^{\text {th }}$ of September at its peak resulting in a major humanitarian crisis.

\section{METHODOLOGY}

The methodology is divided into SAR coherence map generation, and statistical analysis of the coherence maps.

\subsection{SAR Coherence}

Coherence estimation is the amplitude of the complex correlation coefficient of two SAR images (Lopez-Martinez et al., 2004). This estimation is performed pixel by pixel, using the equation:

$$
\gamma=\left|\frac{\frac{1}{N} \Sigma_{i=0}^{N} M_{i} S_{i}^{*}}{\sqrt{\frac{1}{N} \Sigma_{i=0}^{N} M_{i} M_{i}^{*} \frac{1}{N} \Sigma_{i=0}^{N} S_{i} S_{i}^{*}}}\right|
$$

The resultant coherence maps have coherence values ranging from 1 (coherent) to 0 (incoherent).

For this task, in both our study areas, we used VV polarized Sentinel-1 C band imagery with baselines of not more than 100 days for temporal baseline and not more than 150 for the perpendicular baseline (refer to Table 1 and Table 2) and processed them using the SarProZ (Perissin et al., 2011) software by: stacking the images, setting the polarization, selecting the slave and master images and extracting them, image filtering, generating interferograms, generating the coherence maps and finally exporting the coherence maps into TIF format after orthorectification.

\begin{tabular}{|l|l|l|l|l|l|l|l|l|}
\hline Sarpol-e-Zahab & & & & & & & & \\
\hline Master & 20170710 & 20170710 & 20170710 & 20170710 & 20170710 & 20170710 & 20170710 & 20170710 \\
\hline Slave & 20170312 & 20170511 & 20170604 & 20170722 & 20170803 & 20170908 & 20171107 & 20171201 \\
\hline
\end{tabular}

Table 1: Master and slave images selected for experiments in Sarpol-e-Zahab

\begin{tabular}{|l|l|l|l|l|l|l|l|l|}
\hline Puerto Rico & & & & & & & & \\
\hline Master & 20170823 & 20170823 & 20170823 & 20170823 & 20170823 & 20170823 & 20170823 & 20170823 \\
\hline Slave & 20170531 & 20170624 & 20170718 & 20170811 & 20170811 & 20170928 & 20171010 & 20171127 \\
\hline
\end{tabular}

Table 2: Master and slave images selected for experiments in Puerto Rico

Classifying the coherence maps into areas of change and nochange by using a threshold of $>0.6$ (Jendryke et al., 2016) is essential for one to have a better visual impression of the changed and unchanged areas.

\subsection{Land-use Classification}

The ENVI software was used to classify Landsat 5 and Landsat 8 imagery of the study areas into different land-use types and the following land-use classes were identified: built-up, vegetated, water bodies and bare soil. The land-use classes are then converted into polygons and integrated with the coherence images to determine the effect of coherence loss on each land-use class over time and after the occurrence of each disaster.

\section{RESULTS}

\subsection{Coherence Results}

The results show a general loss in coherence over time. In Sarpol Zahab (Figure 1), a comparison of two coherence images (one just before the earthquake and the other soon after the earthquake) shows most of the city in black in 2017/12//01 than in 2017/11/07. This means that there is a high loss $(70.3 \%)$ in coherence in $201712 / 01$ as compared to $37.8 \%$ in $2017 / 11 / 07$.
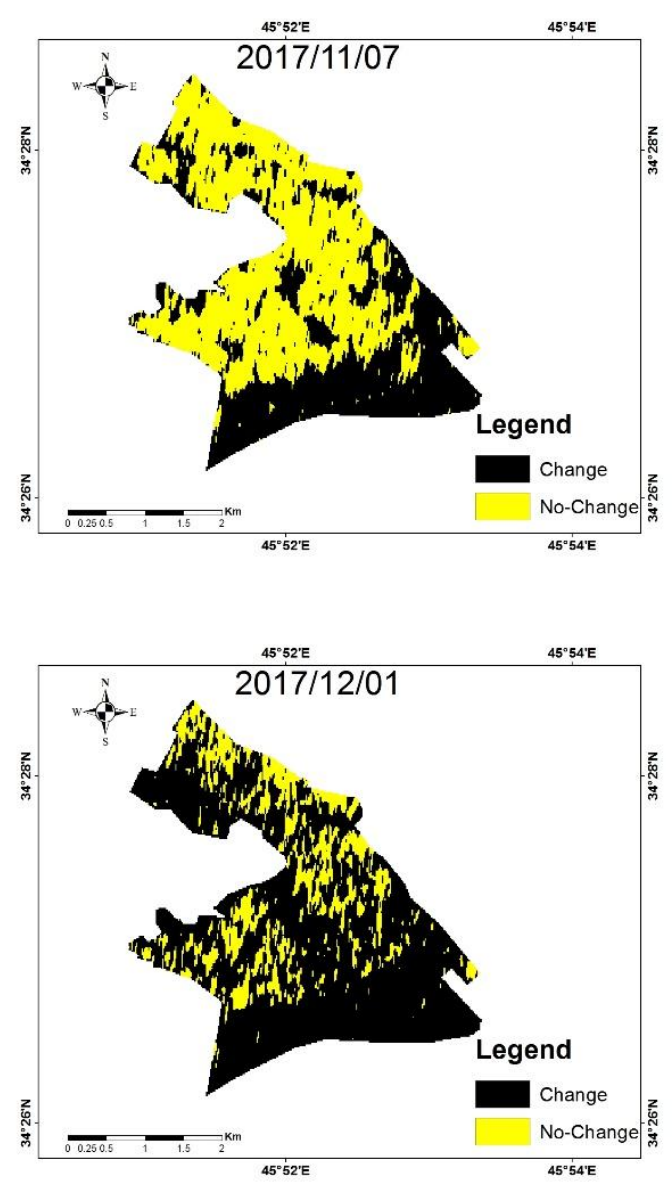

Figure 1: Thresholded coherence images of Sarpol-e-Zahab representing the periods before and after the earthquake

Similarly, results in Puerto Rico (Figure 2) also exhibit a lower loss in coherence (41\% loss in total coherence) in 2017/08/11 as compared to 2017/09/28 (64.4\% loss in total coherence). 

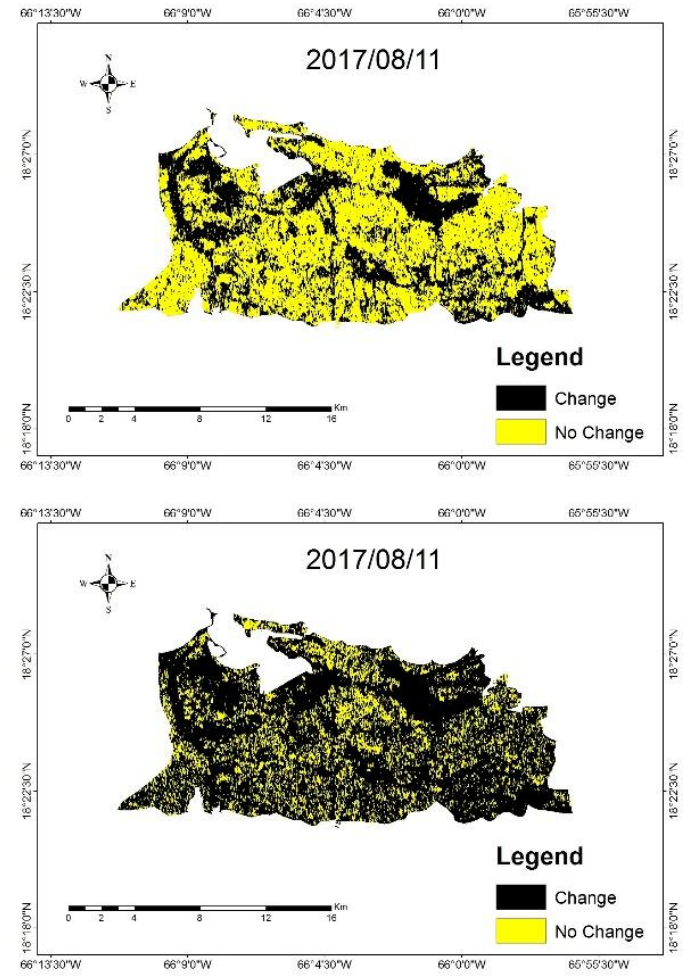

Figure 2: Thresholded coherence images of Puerto Rico representing the periods before and after the Hurricane

\subsection{Classification Results}

In both study areas, we observe that some parts of the coherence images experience coherence loss in pre and post disaster coherence maps. For example, in Sarpol-e-Zahab, there is coherence loss in the southern part of the city even before the earthquake, this phenomenon can be attributed to the land-use type. Therefore, the study areas were divided into different landuses and coherence loss over time was calculated for each landuse. The classification results show a significant drop in the average coherence from $>0.6$ to below 0.5 after the occurrence of the earthquake event. The hurricane event also shows a reduction of the coherence for all land-use classes with average coherence dropping to 0.5 for built up and $<0.5$ for vegetation areas. However, water bodies average coherence remains below 0.5 throughout the period.

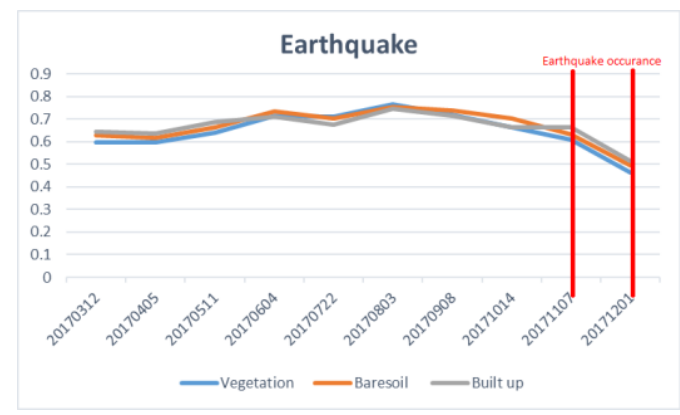

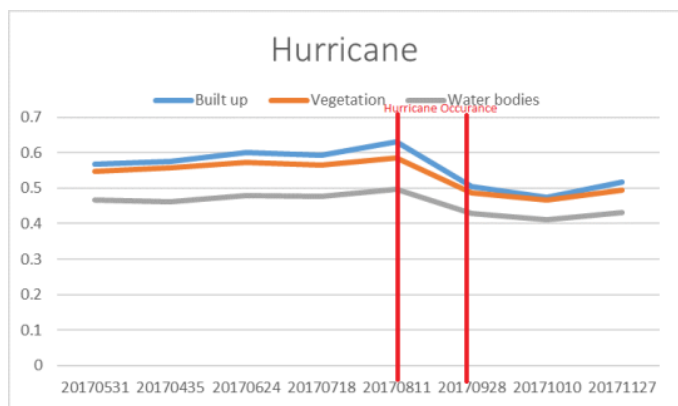

Figure 3: Land-use class graphs showing coherence loss over time for different land-uses

\subsection{Standard Deviation Results}

The study areas were divided into street blocks, average coherence was calculated for each street and the standard deviation for each street block was also calculated over time for each street block. Results for Sarpol-e-Zahab show a higher standard deviation in some street blocks in the map after the disaster as compared to the map before the disaster as shown in Figure 4. This is an indication of the effects of the earthquake.
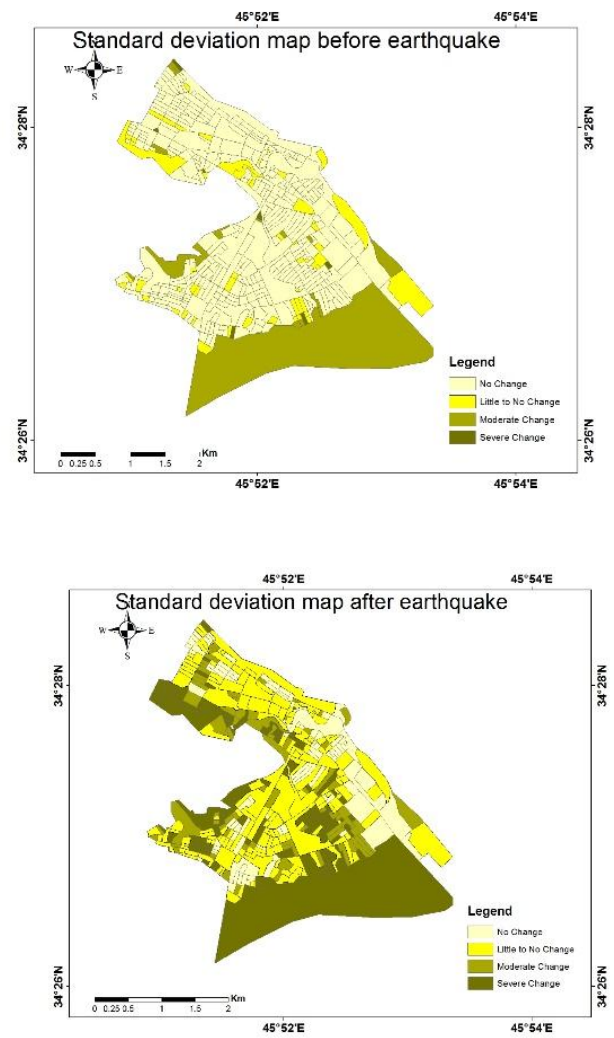

Figure 4: Standard deviation maps for Sarpol-e-Zahab before and after the earthquake.

Similarly, street blocks in Puerto Rico in Figure 6 show a high standard deviation in street blocks after the hurricane. However, even though water bodies such as lagoons have low coherence, there are seen to have low standard deviation as well. This shows that the 
Hurricane has little to no effect on the water bodies as shown in the land-use classification results.
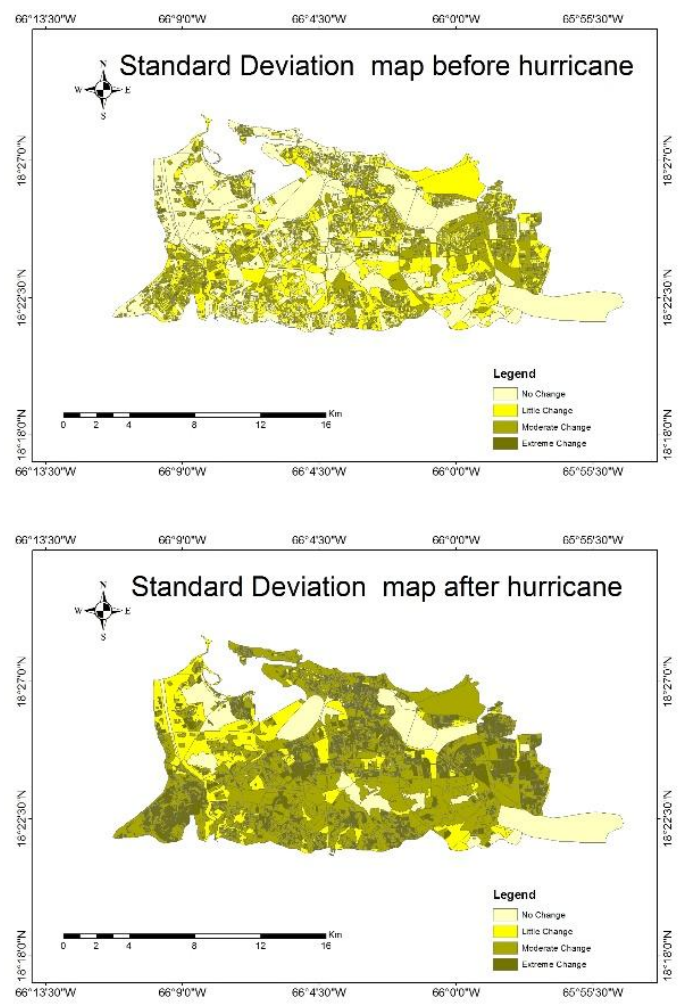

Figure 5: Standard deviation maps for Puerto Rico before and after the Hurricane.

\section{CONCLUSION AND DISCUSSION}

In the experiments, the pre-event and post event results show significant coherence loss after a disaster has occurred. Further analysis by way of calculating standard deviation for street blocks also revealed that some street blocks were affected by the disasters more than others. Therefore, the CCD technique is a useful method in measuring urban change in areas that have been affected by disasters. However, although the CCD technique can detect small changes, it is not a good indicator of the intensity of change. Furthermore, the technique is not very useful in vegetated areas, which are constantly unstable and can only be used in urban built up areas.

The study focuses on urban areas affected by natural disasters and uses the CCD technique to detect changes that have occurred in the areas. The results show general coherence loss before each disaster and massive coherence loss after each disaster. Classifying the areas into various land-use classes shows a significant loss in average coherence after each disaster for all classes except for the water bodies in Puerto Rico.
The work presented here was supported by the Natural Science Foundation of China (Grant No.61331016). The authors would like to thank Daniele Perissin for providing the SarProZ software to support this research.

\section{REFERENCES}

Dong, Y., Li, Q., Dou, A., and Wang, X., 2011. Extracting damages caused by the 2008 Ms 8.0 Wenchuan earthquake from SAR remote sensing data: Journal of Asian Earth Sciences, v. 40, no. 4 , p. 907-914.

He, M., and He, X., 2009. Urban change detection using coherence and intensity characteristics of multi-temporal SAR imagery, in Proceedings Synthetic Aperture Radar, 2009. APSAR. 2nd Asian-Pacific Conference on2009, IEEE, p. 840843.

Jendryke, M., Balz, T., and Liao, M., 2016. Observing urban built-up change in shanghai with SAR imagery, in Proceedings Geoscience and Remote Sensing Symposium (IGARSS), 2016 IEEE International, IEEE, p. 1788-1791.

Jendryke, M., Balz, T., McClure, S. C., and Liao, M., 2017. Putting people in the picture: Combining big location-based social media data and remote sensing imagery for enhanced contextual urban information in Shanghai: Computers, Environment and Urban Systems, v. 62, p. 99-112.

Li, X., Yang, W., Ao, T., Li, H., and Chen, W., 2011. An improved approach of information extraction for earthquakedamaged buildings using high-resolution imagery: Journal of Earthquake and Tsunami, v. 5, no. 04, p. 389-399.

Li, X., Yu, L., Xu, Y., Yang, J., and Gong, P., 2016. Ten years after Hurricane Katrina: monitoring recovery in New Orleans and the surrounding areas using remote sensing: Science bulletin, v. 61 , no. 18 , p. 1460-1470.

Liao, M., Jiang, L., Lin, H., and Li, D., 2005. Urban change detection using coherence and intensity characteristics of multitemporal ERS-1/2 Imagery, in Proceedings Fringe, Workshop2006, Volume 610.

Lopez-Martinez, C., Fabregas, X., Pottier, E., and Polarimetrie, 2004. E. I. R.-T., A new alternative for SAR imagery coherence estimation, in Proceedings Proc. 5th European Conference on Synthetic Aperture Radar (EUSAR'04).

Marx, A. J., 2016. Detecting urban destruction in Syria: A landsat-based approach: Remote Sensing Applications: Society and Environment, v. 4, p. 30-36.

Matsuoka, M., and Yamazaki, F., 2006. Use of SAR imagery for monitoring areas damaged due to the Mid Java, Indonesia earthquake, in Proceedings Proceedings of 4th international workshop on remote sensing for post-disaster response.

Potin, P., Rosich, B., Grimont, P., Miranda, N., Shurmer, I., O'Connell, A., Torres, R., and Krassenburg, M., 2016. Sentinel-1 mission status, in Proceedings EUSAR 2016: 11th European

\section{ACKNOWLEDGMENTS}


Conference on Synthetic Aperture Radar, Proceedings of, VDE, p. $1-6$.

Rana, M. S., Gunasekara, K., Hazarika, M. K., Samarakoon, L., and Siddiquee, M., 2010. Application of remote sensing and GIS for cyclone disaster management in coastal area: A case study at Barguna district, Bangladesh: International Archives of the Photogrammetry, Remote Sensing and Spatial Information Science, v. 38, no. Part 8, p. 122-126.

Wang, F., and Xu, Y. J., 2010. Comparison of remote sensing change detection techniques for assessing hurricane damage to forests: Environmental monitoring and assessment, v. 162, no. 14, p. 311-326.

Yi, L., Shao-hong, W., Zhong-chun, X., and Erfu, D., 2011. Methodology for assessment and classification of natural disaster risk: A case study on seismic disaster in Shanxi Province: 地理 研究, v. 30, no. 2, p. 195-208.

Zhou, L., Wu, X., Xu, Z., and Fujita, H., 2017. Emergency Decision Making for Natural Disasters: An Overview: International Journal of Disaster Risk Reduction. 